\title{
Room Temperature N-Arylation of 1,2,4-Triazoles under Ligand-Free Condition
}

\author{
Nikhil V. Suramwar, ${ }^{1}$ Sanjay R. Thakare, ${ }^{2}$ and Niraj T. Khaty ${ }^{1}$ \\ ${ }^{1}$ Department of Applied Chemistry, Priyadarshini College of Engineering and Technology, Hingna, Maharashtra, \\ Nagpur 440019, India \\ ${ }^{2}$ Department of Chemistry, Government Institute of Science, Civil Lines, Maharashtra, Nagpur 440001, India
}

Correspondence should be addressed to Sanjay R. Thakare, sanjaythakare@yahoo.co.uk

Received 13 June 2012; Accepted 14 August 2012

Academic Editor: Robert Batey

Copyright (C) 2012 Nikhil V. Suramwar et al. This is an open access article distributed under the Creative Commons Attribution License, which permits unrestricted use, distribution, and reproduction in any medium, provided the original work is properly cited.

A simple and efficient method for $\mathrm{N}$-arylation of 1,2,4-triazole at room temperature was described by the use of predominant (111) facet $\mathrm{CuO}$ nanoparticles as a catalyst in ligand-free condition. The catalyst was recyclable, and a variety of substrates give $\mathrm{N}$-arylation product in high yield with short period of reaction time. The wide scope of this catalyst led us to investigate transformations involving less-reactive nitrogen nucleophiles, such as imidazole and pyrazoles. We were pleased to find that various derivatives of azoles were effectively coupled with aryl iodide to afford the desired $\mathrm{N}$-arylated product in excellent yield.

\section{Introduction}

$\mathrm{N}$-Aryl derivatives of azoles are very important organic compounds for organic synthesis because of their wide application in biology and attracted more attention as hole transport molecules for organic light-emitting diodes (LEDs) [1-3]. $\mathrm{N}$-Arylation of azole was carried out by metal-mediated reactions such as the Ullmann coupling $[1,2,4]$, aromatic nucleophilic substitution $[3,5]$, and $\mathrm{Pd}$ or $\mathrm{Cu}$ catalyzed arylation [6]. However, the employment of chelating ligand, stoichiometric amount of $\mathrm{Cr}(\mathrm{CO})_{3}$, and harsh reaction conditions diminished the applicability of these methods, especially for large-scale production. The transition-metalcatalyzed $\mathrm{N}$-arylation of azoles with aryl halides is one of the most efficient and powerful methods for the synthesis of $\mathrm{N}$-aryl derivatives $[7,8]$. However, current methods have some potential limitations because these transformations often use expensive transition-metal catalyst as palladium [9], rhodium [10], nickel [11], and cobalt [12] complexes. Thus, screening out inexpensive and environmentally benign metal catalysts for the $\mathrm{N}$-arylation of azoles still remains a great challenge [13]. Inexpensive copper catalysts bearing various ligands provided a highly economical and efficient method for $\mathrm{N}$-arylation of nitrogen-containing heterocycles with aryl halides. The ligands employed in the $\mathrm{Cu}$-catalyzed reactions included beta-diketones [14], 1,2-diamines [15], phenanthrolines [16], bipyridines [17] $\alpha$-amino acids [18], phosphines [19], and others [20]. The chelating ligands play an important role in controlling the concentration of active catalytic species, but they might contaminate the final products [21]. Ligand-free catalysts could be a good alternative to avoid the inconvenience of ligand removal from reaction mixtures. In the past years, $\mathrm{CuI}$ [22] and $\mathrm{Cu}_{2} \mathrm{O}$ [23] have been successfully employed as catalysts for this cross-coupling reaction in the absence of organic ligands. However, these catalytic systems often required excess substrates or high catalyst loadings [24]. It was reported that simple inorganic copper (II) salts catalyzed such coupling reactions without extra ligands were of limited scope [25].

The use of $\mathrm{CuO}$ nanoparticle for cross-coupling reaction was first reported by Rout et al. [26]. CuO nanomaterials containing high surface area and reactive morphologies have been studied as effective catalysts for organic synthesis $[27,28]$. $\mathrm{CuO}$ nanomaterials were of considerable interest due to role in catalysis, in metallurgy, and in hightemperature superconductors $[29,30]$. These nanoparticles were found to be effective catalysts for $\mathrm{CO}$ and $\mathrm{NO}$ oxidation 


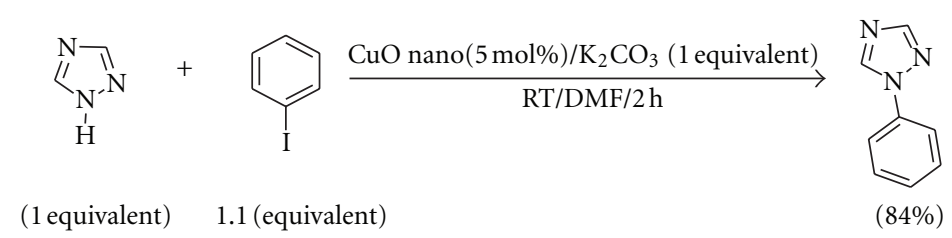

Scheme 1: N-arylation of 1,2,4-triazole.

as well as oxidation of volatile organic chemicals such as methanol $[31,32]$. Recently, Kantam et al. reported the asymmetric hydrosilylation of prochiral ketones, asymmetric direct aldol reaction, and $\mathrm{N}$-arylation of heterocycles using nanocrystalline $\mathrm{CuO}[33,34]$.

The (111) plane of $\mathrm{CuO}$ nanoparticles contains more active sites with higher density as compared to bulk $\mathrm{CuO}$ and therefore these sites actively participated in the catalysis reactions. Previously we shown an excellent catalytic activity of these predominant (111) facet nanoparticles in $\mathrm{N}$-arylation of indoles [35], herein we further extended our study in case of $\mathrm{N}$-arylation of azoles and reported our progress in the $\mathrm{N}$ arylation of azoles with optimum conditions. It was found that, the catalytic activity of these predominant (111) facet $\mathrm{CuO}$ nanoparticles was very high as $\mathrm{N}$-arylation of $1,2,4-$ triazole was carried out even at room temperature with lesser reaction time and excellent yield. The main aim of our study is to give simple and efficient method for $\mathrm{N}$-arylation of azoles by the use of highly active predominant (111) faceted $\mathrm{CuO}$ nanoparticles as a heterogeneous catalyst in a ligand free condition.

\section{Result and Discussion}

The $\mathrm{CuO}$ nanoparticles with predominant (111) plane were fabricated by thermal-assisted green strategy at reflux temperature within short period of time in our laboratory as reported [35].

2.1. Reactions of 1,2,4-Triazole with Aryl Iodide. Recently, there was a report of $\mathrm{Cu}$ catalyzed $\mathrm{N}$-arylation of azoles with aryl halide in presence of ligand but the longer reaction time and difficulty in separation of ligand limits the method [36], whereas in our method, we can easily separate $\mathrm{CuO}$ nanocatalyst and recycled it for at least five times without much loss in yield of the product.

Initially, the reaction of $\mathrm{N}$-arylation of 1,2,4-triazole with aryl iodides was investigated (Scheme 1).

The reaction with iodobenzene occurred at room temperature to give 1-phenyl- $1 \mathrm{H}$-1,2,4-triazole in good yield (84\%), whereas 4-nitro-1-iodobenzene shows greater reactivity towards 1,2,4-triazole than iodobenzene with yield around (91\%). Under similar condition, electron-rich 4iodoanisole and satirically hindered 2-iodotoluene show less reactivity towards 1,2,4-triazole (Table 1, Entry 5 and 6). We carried reactions at different temperatures in order to study the effect of temperature on yield of product but there was not much considerable increase in the yield of product with increase in temperature.
$\mathrm{N}$-arylation of 1,2,4-triazole was effective under air, Iodobenzene exhibited greater reactivity compared to bromobenzene. Under these conditions, chlorobenzene show less reactivity as compared to bromobenzene and Iodobenzene. The order of reactivity was iodobenzene $>$ bromobenzene $>$ chlorobenzene (Table 1, entries 2, 3, and 4). There was no reaction possible in the absence of $\mathrm{CuO}$ nanoparticles.

To our best knowledge, this is the first report of room temperature N-Arylation of 1,2,4-triazole. The reactions were clean and no other impurity due to $C$-arylation or biaryl was obtained.

Reaction of iodobenzene with triazole was examined with various kinds of bases. N-Arylation preceded using carbonates and yield increased in order to increase basicity. However, use of $\mathrm{Cs}_{2} \mathrm{CO}_{3}$ gave no substantial amount of the product, nor did t-BuONa.

In our catalytic system, $\mathrm{K}_{2} \mathrm{CO}_{3}$ and $\mathrm{Rb}_{2} \mathrm{CO}_{3}$ worked very well. Employment of the stronger bases might deactivate the $\mathrm{CuO}$ nanocatalyst. Although employing 0.5 equivalent of a base gave an acceptable yield, the reaction was accelerated using 1 equivalent of the base. $\mathrm{N}$-Arylation of imidazole and pyrazole proceeded similarly. As described above, $\mathrm{K}_{2} \mathrm{CO}_{3}$ and $\mathrm{Rb}_{2} \mathrm{CO}_{3}$ promoted good activity in this reaction and the use of $\mathrm{K}_{2} \mathrm{CO}_{3}$ was more preferable practically (Table 2, entry 5 and 10). Reactions of triazole with iodobenzene was carried out in toluene at room temperature for $12 \mathrm{~h}$ to afford the desired product in $65 \%$ yield and, with acetonitrile, methanol, and chloroform, the conversion was less as compared to toluene (Table 2). Therefore, we examined the synthesis of $\mathrm{N}$-arylation of triazole in the presence of $5 \mathrm{~mol} \%$ of $\mathrm{CuO}$ nanocatalyst and 1 equivalent of $\mathrm{K}_{2} \mathrm{CO}_{3}$ with DMF as a solvent.

2.2. N-Arylation of Imidazole and Pyrazole. We extended our study in case of azoles such as imidazole and pyrazole (Table 3). Initially, the reaction was carried out at room temperature but yield of product was very less. Increased in temperature increases the percentage yield and in $3 \mathrm{~h}$ of reflux, we get $\mathrm{N}$-arylated product with excellent yield up to $97 \%$ (Scheme 2). This might because of less reactive nature of imidazole and pyrazole which makes abstraction of hydrogen from nucleophile difficult at room temperature and $\mathrm{N}$-arylation reaction occurred at refluxed temperature.

All reactions were monitored by Co-TLC and the final product characterized by LCMS, ${ }^{1} \mathrm{H}$ NMR, and ${ }^{13} \mathrm{C}$ NMR.

2.3. Comparison of Catalytic Activity. We compared the catalytic activity of these predominant (111) facet $\mathrm{CuO}$ 
TABLE 1: N-arylation of 1,2,4 triazoles.

Entry

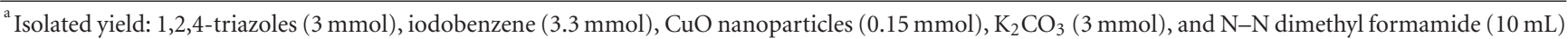
at room temperature.

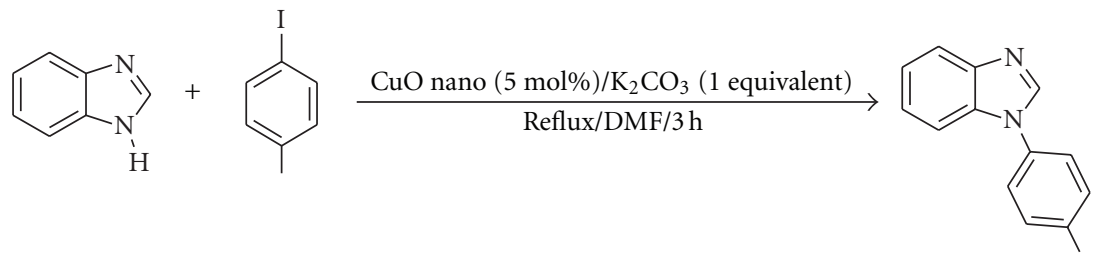

(1 equivalent) 1.1 (equivalent)

$(97 \%)$

Scheme 2: N-arylation of benzimidazole.

TABLE 2: Optimization of reaction condition for the $\mathrm{N}$-arylation of 1,2,4-triazole with iodobenzene.

\begin{tabular}{lcccc}
\hline Entry & Solvent & Base & Reaction time $(\mathrm{h})$ & (Isolated yield) $^{\mathrm{a}}$ \\
\hline 1 & Toluene & $\mathrm{K}_{2} \mathrm{CO}_{3}$ & 12 & $65 \%$ \\
2 & $\mathrm{CH}_{3} \mathrm{CN}$ & $\mathrm{K}_{2} \mathrm{CO}_{3}$ & 12 & $40 \%$ \\
3 & $\mathrm{CH}_{3} \mathrm{OH}$ & $\mathrm{K}_{2} \mathrm{CO}_{3}$ & 12 & $25 \%$ \\
4 & $\mathrm{CHCl}_{3}$ & $\mathrm{~K}_{2} \mathrm{CO}_{3}$ & 12 & $15 \%$ \\
5 & $\mathrm{DMF}$ & $\mathrm{K}_{2} \mathrm{CO}_{3}$ & 2 & $84 \%$ \\
6 & $\mathrm{DMF}$ & $\mathrm{K}_{2} \mathrm{CO}_{3}$ & 8 & $84 \%$ \\
7 & $\mathrm{DMF}$ & $\mathrm{CS}_{2} \mathrm{CO}_{3}$ & 5 & $45 \%$ \\
8 & $\mathrm{DMF}$ & $\mathrm{t}-\mathrm{BuONa}_{2}$ & 5 & $55 \%$ \\
9 & $\mathrm{DMF}$ & $\mathrm{NaOH}_{10}$ & 5 & $35 \%$ \\
\hline
\end{tabular}

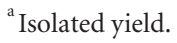

nanoparticles with commercially available $\mathrm{CuO}$ nanoparticles and bulk $\mathrm{CuO}$ powder (purchased from Merck) and results are tabulated in Table 4 . These results clearly show higher catalytic activity of predominant (111) facet $\mathrm{CuO}$ nanoparticles in $\mathrm{N}$-arylation of azoles.

2.4. Effect of Catalyst Concentration. The effect of catalyst concentration on yield of product was studied. The reaction was carried out with varying amount of $\mathrm{CuO}$ catalyst concentration and results are tabulated in Table 5. As the concentration of catalyst was increased from $2.5 \mathrm{~mol} \%$ to $5 \mathrm{~mol} \%$, the yield of the product was increased from $60 \%$ to $97 \%$ further increase in catalyst concentration did not affect overall yield of product.

2.5. Mechanism. The greater catalytic activity of $\mathrm{CuO}$ nanoparticles with respect to bulk $\mathrm{CuO}$ powder indicated that reactions were heterogeneous and occurred on the surface of predominant (111) facet nanocatalyst. Thus, the $\mathrm{CuO}$ nanoparticles might undergo reaction with aryl halide to give intermediate $\mathrm{X}$, where the excess positive charge generated over iodine could be shared among the $\mathrm{CuO}$ nanoparticles 
TABLE 3: N-arylation of imidazole and pyrazole.

Entry

${ }^{\mathrm{a}}$ Isolated yield: azole $(3 \mathrm{mmol})$, iodobenzene $(3.3 \mathrm{mmol})$, $\mathrm{CuO}$ nanoparticles $(0.15 \mathrm{mmol}), \mathrm{K}_{2} \mathrm{CO}_{3}(3 \mathrm{mmol})$, and $\mathrm{N}-\mathrm{N}$ dimethyl formamide $(10 \mathrm{~mL})$ at reflux for $3 \mathrm{~h}$.

TABLE 4: Comparison of catalytic activity of (111) facet $\mathrm{CuO}$ nanoparticle.

\begin{tabular}{|c|c|c|c|c|c|}
\hline Entry & Product & Temperature/time (h) & $\begin{array}{c}\text { Synthesized } \\
\mathrm{CuO} \text { nano }(\text { yield } \%)^{\mathrm{a}}\end{array}$ & $\begin{array}{c}\text { Commercial } \mathrm{CuO} \\
\text { nano }(\text { yield } \%)^{\mathrm{b}}\end{array}$ & 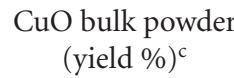 \\
\hline 1 & & $\mathrm{RT} / 2 \mathrm{~h}$ & $84 \%$ & $45 \%$ & No reaction \\
\hline 2 & & $\mathrm{RT} / 2 \mathrm{~h}$ & $91 \%$ & $52 \%$ & No reaction \\
\hline 3 & & $\begin{array}{c}\text { Refluxed } \\
\text { temperature } / 3 \mathrm{~h}\end{array}$ & $97 \%$ & $40 \%$ & $12 \%$ \\
\hline 4 & & $\begin{array}{c}\text { Refluxed } \\
\text { temperature } / 3 \mathrm{~h}\end{array}$ & $98 \%$ & $48 \%$ & $15 \%$ \\
\hline 5 & & $\begin{array}{c}\text { Refluxed } \\
\text { temperature/3 h }\end{array}$ & $86 \%$ & $40 \%$ & $10 \%$ \\
\hline 6 & & $\begin{array}{c}\text { Refluxed } \\
\text { temperature } / 3 \mathrm{~h}\end{array}$ & $83 \%$ & $40 \%$ & $12 \%$ \\
\hline
\end{tabular}

$\overline{\mathrm{a}, \mathrm{b}, \mathrm{c}}$ Isolated yield. 
TABLE 5: Effect of catalyst concentration on the $\mathrm{N}$-arylation of benzimidazole.

\begin{tabular}{lccc}
\hline Entry & Catalyst conc. $(\mathrm{mol} \%)$ & Reaction time $(\mathrm{h})$ & Yield $(\%)^{\mathrm{a}}$ \\
\hline 1 & 2.5 & 3 & 60 \\
2 & 5 & 3 & 97 \\
3 & 10 & 3 & 97 \\
4 & 15 & 3 & 96 \\
\hline
\end{tabular}

a Isolated yield.

TABLe 6: Recyclability of CuO nanoparticles as a catalyst.

\begin{tabular}{lcc}
\hline Entry & Cycle & $($ Yield \%) \\
\hline 1 & 1 st & 97 \\
2 & 2 nd & 93 \\
3 & 3 rd & 90 \\
4 & 4 th & 80 \\
5 & 5 th & 78 \\
\hline
\end{tabular}

asolated yield, reaction conditions: azole $(3 \mathrm{mmol})$, iodobenzene (3.3 mmol), $\mathrm{CuO}$ nanoparticles $(0.15 \mathrm{mmol}), \mathrm{K}_{2} \mathrm{CO}_{3}(3 \mathrm{mmol})$, and $\mathrm{N}-\mathrm{N}$ dimethyl formamide $(10 \mathrm{~mL})$ at reflux for $3 \mathrm{~h}$.

present on the surface of the cluster (Scheme 3). Later, X might undergo reaction with triazole to give intermediate $\mathrm{Y}$ that can complete the catalytic cycle by the formation of the $\mathrm{N}$-arylated product. The $\mathrm{CuO}$ nanoparticles become free at the end of reaction.

2.6. Recyclability of Catalyst. Finally, the stability and activity of the catalyst was tested in the recycle-use experiments. The $\mathrm{CuO}$ nanoparticles recycled for five times without loss of its catalytic activity (Table 6). The used catalyst was then separated by centrifugation and washed with hot water twothree times before being recycled in next reaction. It was found that during recycle experiments, there was not much loss in yield of the product which shows the recyclability and reusability of catalyst without significant loss of its catalytic activity.

\section{Experimental Section}

3.1. General Procedure for the N-Arylation of 1,2,4-Triazole. 1,2,4-Triazole $(3 \mathrm{mmol})$, iodobenzene $(3.3 \mathrm{mmol}), \mathrm{CuO}$ nanoparticles $(0.15 \mathrm{mmol}), \mathrm{K}_{2} \mathrm{CO}_{3}(3 \mathrm{mmol})$, and $\mathrm{N}-\mathrm{N}$ dimethyl formamide $(10 \mathrm{~mL})$ were taken in a glass reactor. Stirred the reaction mixture at room temperature and monitored by Co-TLC till completion of reaction. After completion of reaction, dilute the reaction mixture with $20 \mathrm{~mL}$ water. The entire reaction mixture was washed with ethyl acetate $(2 \times 10 \mathrm{~mL})$. Aqueous layer was centrifuged to recover $\mathrm{CuO}$ nanocatalyst. The combined organic extracts were washed with brine and dried by sodium sulphate. Solvent was evaporated under reduced pressure and the crude product was purified by flash column chromatography on silica gel with ethyl acetate: petroleum ether $(1: 9)$ as eluent to yield analytically pure product.
1-Phenyl-1H-1,2,4-Triazole (1a). Nature: light yellow oil. ${ }^{1} \mathrm{H}$ NMR $400 \mathrm{MHz}\left(\mathrm{CDCl}_{3}\right): \delta 7.26(\mathrm{~s}, 2 \mathrm{H}), 7.34(\mathrm{~s}, 3 \mathrm{H}), 8.32(\mathrm{~d}$, $J=8.4 \mathrm{~Hz}, 1 \mathrm{H}), 8.64(\mathrm{~s}, 1 \mathrm{H}) .{ }^{13} \mathrm{C}$ NMR $100 \mathrm{MHz}\left(\mathrm{CDCl}_{3}\right)$ : $\delta$ 119.20, 123.25, 123.39, 129.34, 129.65, 135.18, 146.34 . LCMS: $(\mathrm{M}+1)=145$.

1-(4-Nitrophenyl)-1H-1,2,4-Triazole (2a). Nature: yellow solid, M.P. $=170-173^{\circ} \mathrm{C} .{ }^{1} \mathrm{H}$ NMR $400 \mathrm{MHz}\left(\mathrm{CDCl}_{3}\right): \delta$ 7.89-7.94 (m, 4H), $8.46(\mathrm{~s}, 1 \mathrm{H}), 8.78(\mathrm{~s}, 1 \mathrm{H}) .{ }^{13} \mathrm{C}$ NMR $100 \mathrm{MHz}\left(\mathrm{CDCl}_{3}\right): \delta 124.85,130.35,130.45,138.65,147.73$, 154.71. LCMS: $(\mathrm{M}+1)=191$.

3.2. General Procedure for N-Arylation of Imidazole and Pyrazole. Azole $(3 \mathrm{mmol})$, iodobenzene $(3.3 \mathrm{mmol}), \mathrm{CuO}$ nanoparticles $(0.15 \mathrm{mmol}), \mathrm{K}_{2} \mathrm{CO}_{3}(3 \mathrm{mmol})$, and $\mathrm{N}-\mathrm{N}$ dimethyl formamide $(10 \mathrm{~mL})$ were taken in a glass reactor fitted with a condenser. Refluxed the mixture and monitored by Co-TLC, till completion of reaction. Workup procedure and purification of products were performed as described for the 1,2,4-triozole reactions.

1-P-Tolyl-1H-benzo[d] imidazole (1b). Nature: oil, ${ }^{1} \mathrm{H}$ NMR $400 \mathrm{MHz}\left(\mathrm{CDCl}_{3}\right): \delta 2.43(\mathrm{~s}, 3 \mathrm{H}), 7.26-7.36(\mathrm{~m}, 6 \mathrm{H}), 7.48(\mathrm{~d}$, $J=8 \mathrm{~Hz}, 1 \mathrm{H}), 7.87(\mathrm{~d}, J=8 \mathrm{~Hz}, 1 \mathrm{H}), 8.09(\mathrm{~s}, 1 \mathrm{H}) .{ }^{13} \mathrm{C} \mathrm{NMR}$ $100 \mathrm{MHz}\left(\mathrm{CDCl}_{3}\right): \delta 21.14,110.53,120.40,122.79,123.67$, $124.00,130.59,133.67,133.79,138.21,142.30,143.58$. LCMS: $(\mathrm{M}+1)=209.10 . \operatorname{IR}\left(\mathrm{cm}^{-1}\right)=3054,3036,1610$, $1515,1486,1453,1375,1320,1287,1227,1203,1140,1109$, 1009, 976, 887, 818, 780, 764, 737, 708, 620, 586, 565.

1-Phenyl-1H-benzol[d][1,2,3]Triazole (2b). Nature: white crystalline solid. M.P. $=86-88^{\circ} \mathrm{C} .{ }^{1} \mathrm{H}$ NMR $400 \mathrm{MHz}$ $\left(\mathrm{CDCl}_{3}\right): \delta(\mathrm{t}, J=7.12 \mathrm{~Hz}, 1 \mathrm{H}), 7.49-7.57(\mathrm{~m}, 2 \mathrm{H}), 7.61(\mathrm{t}$, $J=8.16 \mathrm{~Hz}, 2 \mathrm{H}), 7.75-7.80(\mathrm{~m}, 3 \mathrm{H}), 8.15(\mathrm{~d}, J=8.36 \mathrm{~Hz}$, $1 \mathrm{H}) .{ }^{13} \mathrm{C}$ NMR $100 \mathrm{MHz}\left(\mathrm{CDCl}_{3}\right): 110.39,120.36,122.91$, $124.42,128.26,128.70,129.89,132.33,137.02,146.53$. LCMS: $(\mathrm{M}+1)=195$. IR $(\mathrm{KBr} \mathrm{cm}-1)=3098,3040,2918$, $1655,1595,1560,1500,1458,1290,1275,1244,1188,1143$, $1126,1089,1059,1010,924,785,762,708,694,659,572,517$, 434.

1-Phenyl-1H-Imidazole (3b). Nature: oil. ${ }^{1} \mathrm{H}$ NMR $400 \mathrm{MHz}$ $\left(\mathrm{CDCl}_{3}\right): \delta 7.26(\mathrm{~d}, J=3.76 \mathrm{~Hz}, 1 \mathrm{H}), 7.30(\mathrm{~s}, 1 \mathrm{H}), 7.41(\mathrm{~d}$, $J=6.96 \mathrm{~Hz}, 3 \mathrm{H}), 7.51(\mathrm{t}, J=8.64 \mathrm{~Hz}, 2 \mathrm{H}), 8.05(\mathrm{~s}, 1 \mathrm{H}) .{ }^{13} \mathrm{C}$ $\mathrm{NMR} 100 \mathrm{MHz}\left(\mathrm{CDCl}_{3}\right): \delta 118.53,121.67,127.97,128.93$, $130.01,135.44,136.99$. LCMS $(M+1)=145$.

1-Phenyl-1H-Pyrazole (4b). Nature: oil. ${ }^{1} \mathrm{H}$ NMR $400 \mathrm{MHz}$ $\left(\mathrm{CDCl}_{3}\right): \delta 6.47(\mathrm{~s}, 1 \mathrm{H}), 7.25-7.30(\mathrm{~m}, 1 \mathrm{H}), 7.45(\mathrm{t}, J=$ $8.28 \mathrm{~Hz}, 2 \mathrm{H}), 7.70(\mathrm{t}, J=7.68 \mathrm{~Hz}, 3 \mathrm{H}), 7.94(\mathrm{~s}, 1 \mathrm{H}) .{ }^{13} \mathrm{C}$ NMR $100 \mathrm{MHz}\left(\mathrm{CDCl}_{3}\right): \delta 107.69,115.41,119.27,120.30$, $126.52,126.91,129.47,129.59,140.16,141.10$. LCMS (M + 1) $=145$. 


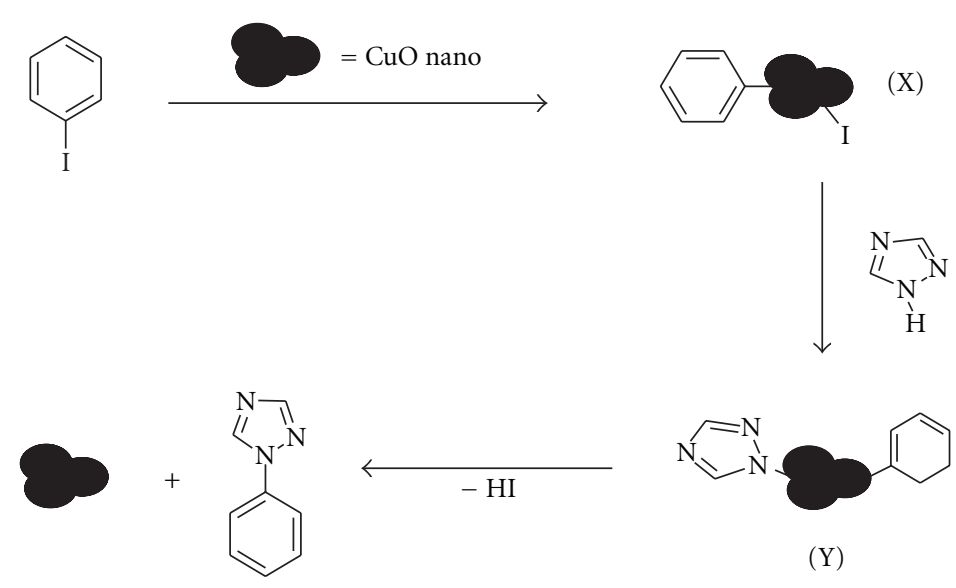

Scheme 3: Proposed mechanism for $\mathrm{N}$-arylation of triazole catalysed by $\mathrm{CuO}$.

\section{Conclusion}

A simple, general, and efficient procedure was described for $\mathrm{N}$-arylation of 1,2,4-triazoles at room temperature with aryl iodides under ligand-free condition by the use of predominant (111) facet $\mathrm{CuO}$ nanoparticles as a catalyst. The catalyst was recyclable, and a variety of substrates undergo reaction in high yield. The wide scope of this catalyst led us to investigate transformations involving less-reactive azoles such as imidazole and pyrazole. We were pleased to found that various azole derivative effectively coupled with aryl iodide to afford the desired $\mathrm{N}$-arylated products in excellent yields. See supplementary material available online at doi:10.1155/2012/515092.

\section{Acknowledgment}

The authors gratefully acknowledge UGC, New Delhi (no. F-39-696/2010(SR) and F-14-11/2008 (inno./ASIST) for financial assistance to carry out this work through major research project and innovative programme.

\section{References}

[1] Y. Kuwabara, H. Ogawa, H. Inada, N. Noma, and Y. Shirota, "Thermally stable multilayered organic electroluminescent devices using novel starburst molecules, $4,4^{\prime}, 4^{\prime \prime}$-tri(Ncarbazolyl)triphenylamine (TCTA) and $4,4^{\prime}, 4^{\prime \prime}$-tris(3-methylphenylphenyl-amino)triphenylamine (m-MTDATA), as holetransport materials," Advanced Materials, vol. 6, no. 9, pp. 677-679, 1994.

[2] N. X. Hu, S. Xie, Z. Popovic, B. Ong, A. M. Hor, and S. Wang, "5,11-dihydro-5,11-di-1-naphthylindolo[3,2b]carbazole: atropisomerism in a novel hole-transport molecule for organic light-emitting diodes," Journal of the American Chemical Society, vol. 121, no. 21, pp. 5097-5098, 1999.

[3] S. Maiorana, C. Baldoli, P. Del Buttero, M. Di Ciolo, and A. Papagni, "Aromatic nucleophilic substitution on haloarene chromium tricarbonyl complexes: mild $\mathrm{N}$-arylation on indoles," Synthesis, no. 5, pp. 735-738, 1998.
[4] A. Kiyomori, J. F. Marcoux, and S. L. Buchwald, "An efficient copper-catalyzed coupling of aryl halides with imidazoles," Tetrahedron Letters, vol. 40, no. 14, pp. 2657-2660, 1999.

[5] W. J. Smith and J. S. Sawyer, "A novel and selective method for the N-arylation of indoles mediated by KF/Al2O3," Tetrahedron Letters, vol. 37, no. 3, pp. 299-302, 1996.

[6] I. P. Beletskaya, D. V. Davydov, and M. Moreno-Mañas, "Pd- and Cu-catalyzed selective arylation of benzotriazole," Tetrahedron Letters, vol. 39, no. 31, pp. 5617-5620, 1998.

[7] G. Mann, J. F. Hartwig, M. S. Driver, and C. F. Rivas, "Palladium-catalyzed $\mathrm{C}-\mathrm{N}\left(\mathrm{sp}^{2}\right)$ bond formation: $\mathrm{N}$ Arylation of aromatic and unsaturated nitrogen and the reductive elimination chemistry of palladium azolyl and methyleneamido complexes," Journal of the American Chemical Society, vol. 120, pp. 827-828, 1998.

[8] K. Prabakaran, P. Manivel, and F. Nawaz Khan, "An effective BINAP and microwave accelerated palladium-catalyzed amination of 1-chloroisoquinolines in the synthesis of new 1,3disubstituted isoquinolines," Tetrahedron Letters, vol. 51, no. 33, pp. 4340-4343, 2010.

[9] A. Klapars, J. C. Antilla, X. Huang, and S. L. Buchwald, "A general and efficient copper catalyst for the amidation of aryl halides and the N-arylation of nitrogen heterocycles," Journal of the American Chemical Society, vol. 123, no. 31, pp. 77277729, 2001.

[10] J. D. Hicks, A. M. Hyde, A. M. Cuezva, and S. L. Buchwald, "Pd-catalyzed N-arylation of secondary acyclic amides: Catalyst development, scope, and computational study," Journal of the American Chemical Society, vol. 131, no. 46, pp. 1672016734, 2009.

[11] M. Kim and S. Chang, "Rhodium(NHC)-catalyzed amination of aryl bromides," Organic Letters, vol. 12, pp. 1640-1643, 2010.

[12] R. Omar-Amrani, A. Thomas, E. Brenner, R. Schneider, and Y. Fort, "Efficient nickel-mediated intramolecular amination of aryl chlorides," Organic Letters, vol. 5, no. 13, pp. 2311-2314, 2003.

[13] P. F. Larsson, A. Correa, M. Carril, P. O. Norrby, and C. Bolm, "Copper-catalyzed cross-couplings with part-permillion catalyst loadings," Angewandte Chemie, vol. 48, no. 31, pp. 5691-5693, 2009.

[14] A. Shafir and S. L. Buchwald, "Highly selective roomtemperature copper-catalyzed C-Ncoupling reactions," 
Journal of the American Chemical Society, vol. 128, pp. 8742-8743, 2006.

[15] J. C. Antilla, J. M. Baskin, T. E. Barder, and S. L. Buchwald, "Copper-diamine-catalyzed N-arylation of pyrroles, pyrazoles, indazoles, imidazoles, and triazoles," Journal of Organic Chemistry, vol. 69, no. 17, pp. 5578-5587, 2004.

[16] H. B. Goodbrand and N. X. Hu, "Ligand-accelerated catalysis of the Ullmann condensation: application to hole conducting triarylamines," The Journal of Organic Chemistry, vol. 64, pp. 670-674, 1999.

[17] R. Gujadhur, D. Venkataraman, and J. T. Kintigh, "Formation of aryl-nitrogen bonds using a soluble copper(I) catalyst," Tetrahedron Letters, vol. 42, no. 29, pp. 4791-4793, 2001.

[18] D. W. Ma, Q. Cai, and H. Zhang, "Mild method for Ullmann coupling reaction of amines and aryl halides," Organic Letters, vol. 5, pp. 2453-2455, 2003.

[19] H. Kaddouri, V. Vicente, A. Ouali, F. Ouazzani, and M. Taillefer, "Copper-catalyzed arylation of nucleophiles by using butadienylphosphines as ligands: mechanistic insight," Angewandte Chemie, vol. 48, no. 2, pp. 333-336, 2009.

[20] E. Haldón, E. Alvarez, M. Carmen Nicasio, and P. J. Pérez, "Dinuclear copper(I) complexes as precatalysts in Ulimann and Goldberg coupling reactions," Organometallics, vol. 28, no. 13, pp. 3815-3821, 2009.

[21] K. Okano, H. Tokuyama, and T. Fukuyama, "Synthesis of secondary arylamines through copper-mediated intermolecular aryl amination," Organic Letters, vol. 5, no. 26, pp. 4987-4990, 2003.

[22] A. Correa and C. Bolm, "Ligand-Free copper-catalyzed Narylation of nitrogen nucleophiles," Advanced Synthesis \& Catalysis, vol. 349, pp. 2673-2676, 2007.

[23] M. Taillefer, N. Xia, and A. Ouali, "Efficient iron/copper co-catalyzed arylation of nitrogen nucleophiles," Angewandte Chemie, vol. 46, no. 6, pp. 934-936, 2007.

[24] Z. J. Liu, J. P. Vors, E. R. F. Gesing, and C. Bolm, "Microwaveassisted solvent- and ligand-free copper-catalysed crosscoupling between halopyridines and nitrogen nucleophiles," Green Chemistry, vol. 13, no. 1, pp. 42-45, 2011.

[25] B. M. Choudary, C. Sridhar, M. L. Kantam, G. T. Venkanna, and B. Sreedhar, "Design and evolution of copper apatite catalysts for $\mathrm{N}$-arylation of heterocycles with chloro- and fluoroarenes," Journal of the American Chemical Society, vol. 127, no. 28, pp. 9948-9949, 2005.

[26] L. Rout, T. K. Sen, and T. Punniyamurthy, "Efficient CuOnanoparticle-catalyzed C-S cross-coupling of thiols with iodobenzene," Angewandte Chemie, vol. 46, no. 29, pp. 55835586, 2007.

[27] L. Rout, S. Jammi, and T. Punniyamurthy, "Novel CuO nanoparticle catalyzed C-N cross coupling of amines with Lodobenzene," Organic Letters, vol. 9, no. 17, pp. 3397-3399, 2007.

[28] M. Kidwai, S. Bhardwaj, and R. Poddar, "C-arylation reactions catalyzed by $\mathrm{CuO}$-nanoparticles under ligand free conditions," Beilstein Journal of Organic Chemistry, vol. 6, article no. 35, 2010.

[29] P. Larsson and A. Andersson, "Complete oxidation of CO, ethanol, and ethyl acetate over copper oxide supported on titania and ceria modified titania," Journal of Catalysis, vol. 179, pp. 72-89, 1998.

[30] B. Raveau, C. Michel, M. Herview, and D. Groult, Superconducting Copper Oxide, Springer, Berlin, Germany, 1991.

[31] Y. Liu, Q. Fu, and M. F. Stephanopoulos, "Preferential oxidation of $\mathrm{CO}$ in $\mathrm{H}_{2}$ over $\mathrm{CuO}-\mathrm{CeO}_{2}$ catalysts," Catalysis Today, vol. 93-95, pp. 241-246, 2004.
[32] A. A. Martinez, A. B. Hungria, M. Fernandez-Garcia, J. C. Conesa, and J. C. Munuera, "Interfacial Redox processes under $\mathrm{CO} / \mathrm{O}_{2}$ in a Nanoceria-supported copper oxide catalyst," The Journal of Physical Chemistry B, vol. 108, pp. 17983-17991, 2004.

[33] M. L. Kantam, S. Laha, J. Yadav, P. R. Likhar, B. Sreedhar, and B. M. Choudary, "Asymmetric hydrosilylation of prochiral ketones catalyzed by nanocrystalline copper(II) oxide," Advanced Synthesis and Catalysis, vol. 349, no. 10, pp. 17971802, 2007.

[34] M. L. Kantam, T. Ramani, L. Chakrapani, and K. V. Kumar, "Direct asymmetric aldol reactions catalyzed by nanocrystalline copper(II) oxide," Tetrahedron Letters, vol. 49, no. 9, pp. 1498-1501, 2008.

[35] N. V. Suramwar, S. R. Thakare, N. N. Karade, and N. T. Khaty, "Green synthesis of predominant $\left(\begin{array}{lll}1 & 1 & 1\end{array}\right)$ facet $\mathrm{CuO}$ nanoparticles: Heterogeneous and recyclable catalyst for $\mathrm{N}$ arylation of indoles," Journal of Molecular Catalysis A, vol. 359, pp. 28-34, 2012.

[36] D. Wang, F. Zhang, D. Kuang, J. Yu, and J. Li, "A highly efficient $\mathrm{Cu}$-catalyst system for $\mathrm{N}$-arylation of azoles in water," Green Chemistry, vol. 14, no. 5, pp. 1268-1271, 2012. 


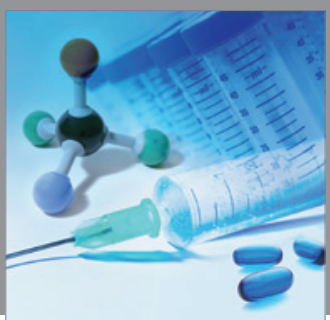

International Journal of

Medicinal Chemistry

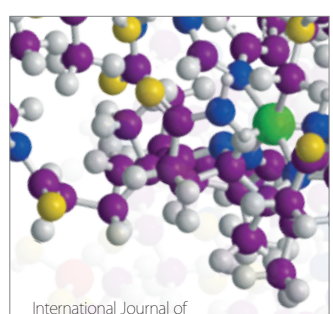

Carbohydrate Chemistry

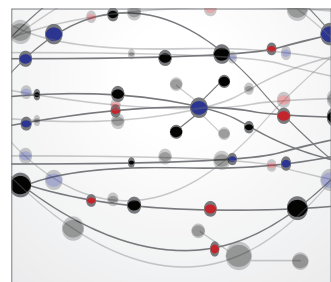

The Scientific World Journal
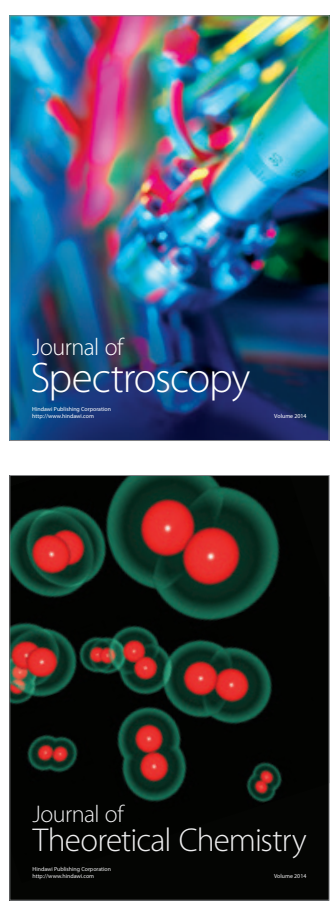
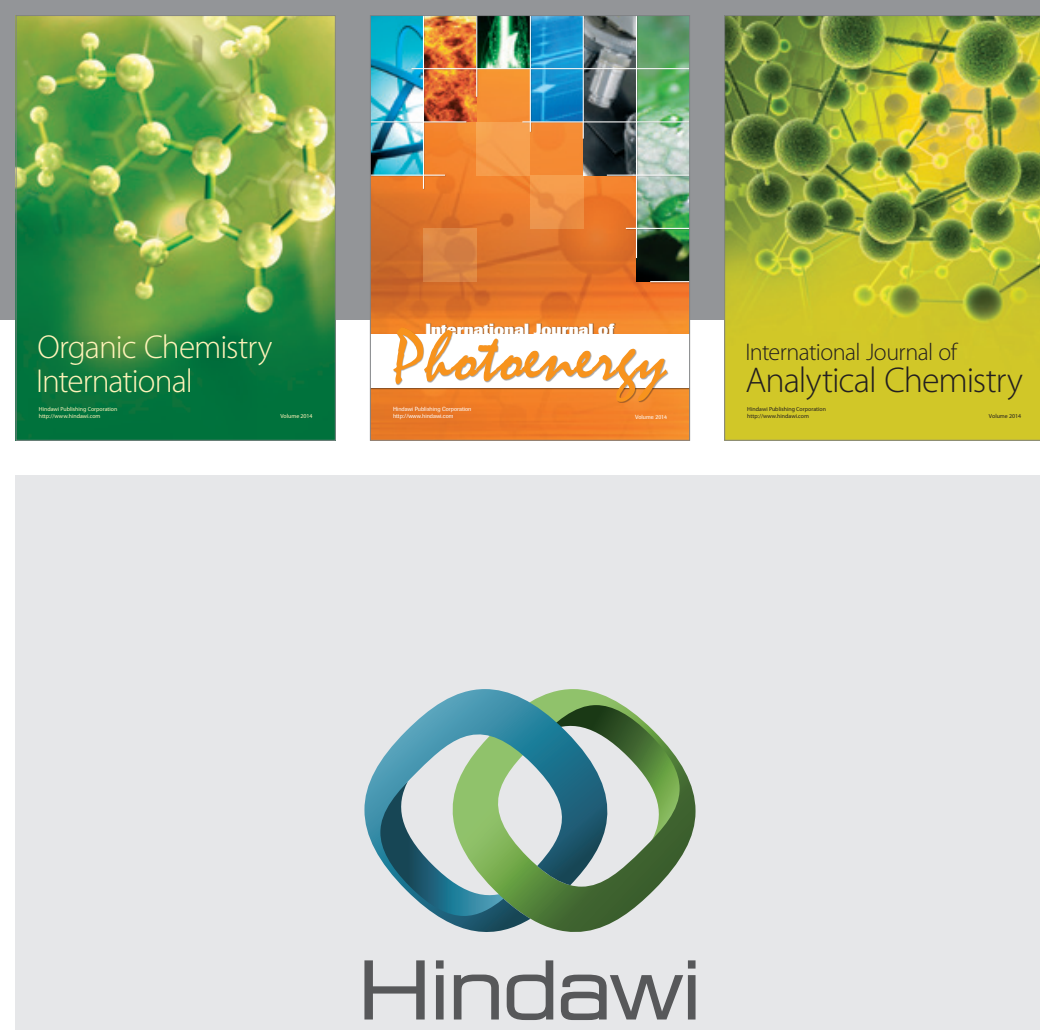

Submit your manuscripts at

http://www.hindawi.com
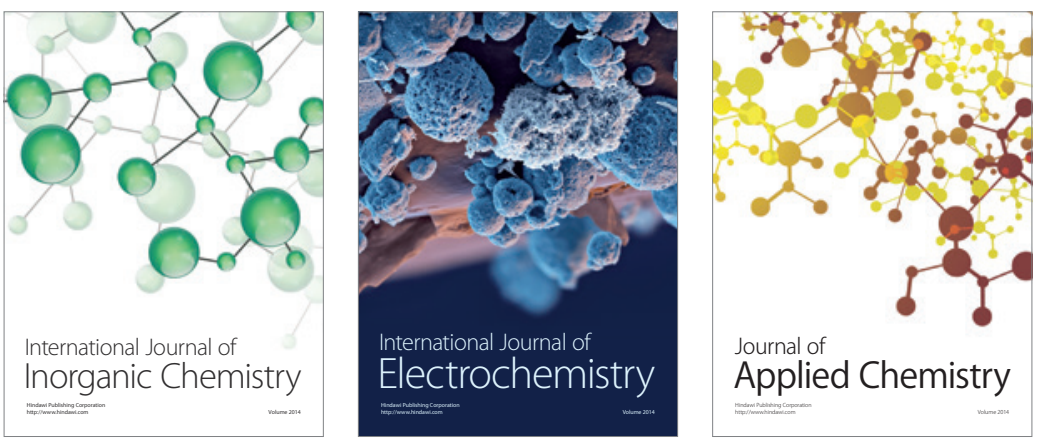

Journal of

Applied Chemistry
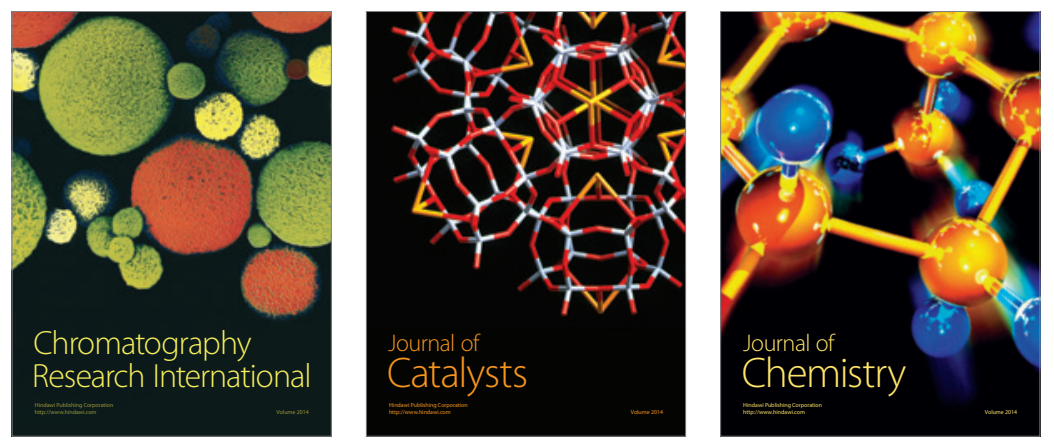
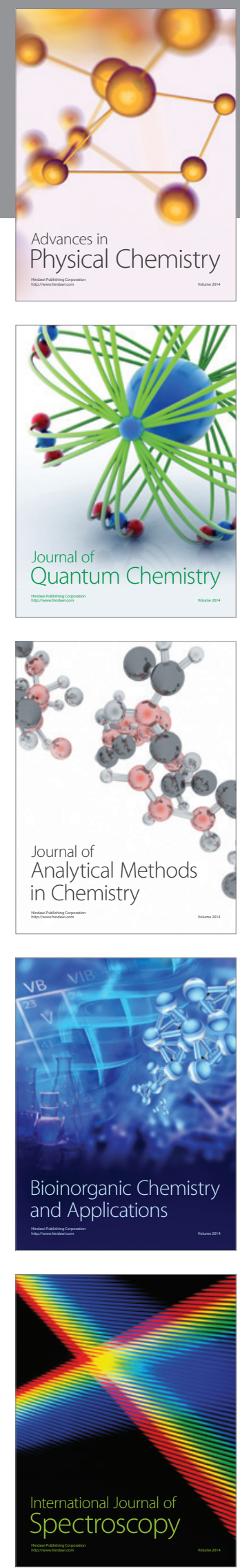